\title{
РАЗДЕЛЕНИЕ И КОЛИЧЕСТВЕННОЕ ОПРЕДЕЛЕНИЕ ХЛОРИСТОГО ГЕРАНИЛДИМЕТИЛФЕНИЛАММОНИЯ В СМЕСИ ЕГО ГОМОЛОГОВ
}

Хлористый геранилдиметилфениламмоний<smiles>CN(C)c1ccc(Cl)cc1</smiles>

и его гомологи с общей формулой

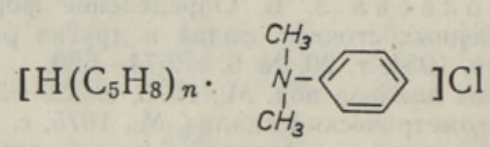

образуются при селективном взаимодействии N,N-диметиланилина с первичными аллильными галогенопроизводными хлортеломеров изопрена (главным образом геранил- и фарнезилхлоридами) и отделяются от остальных продуктов реакции $55 \%$-ным метанолом в виде четвертичных аммониевых солей |[ $\left.{ }^{1}\right]$.

Нами разработана методика разделения хлористого геранилдиметилфениламмония в смеси его гомологов при помощи электрофореза на бумаге. В качестве буферного раствора использовался раствор 0,2 $\mathrm{M}$ уксусной кислоты, в качестве хроматографической бумаги - бумага марки FN-1 и FN-12. Количественное определение компонентов выполнялось двумя способами: 1) по площадям зон разделенных компонентов и 2) разложением разделенных компонентов кипячением в с последующим определением освобожденного эквивалентного количества N,N-диметиланилина при помощи УФ-спектрофотометра.

Разработанная методика является примером развития и применения электрофореза на бумаге при химическом анализе смеси четвертичных аммониевых солей.

\section{Экспериментальная часть}

Использованы следующие исходные вещества: 1) фракция монотерпеновых хлоридов $\left.\mathrm{C}_{10} \quad\left(n_{D}^{20} \quad 1,4800 ; \quad d_{4}^{20} \quad 0,9465 ; \mathrm{Cl}_{\text {перв. }} 9,2 \%\right) ; 2\right)$ фракция сесквитерпеновых хлоридов $\left.\mathrm{C}_{15}\left(n_{D}^{20} 1,4860 ; d_{4}^{20} 0,9539 ; \mathrm{Cl}_{\text {перв }}, 6,1 \%\right) ; 3\right)$ суммарный теломер изопрена с его гидрохлоридами, содержащий (\%): геранилхлорида 28 , фарнезилхлорида 8 и хлоридов политерпеновой фракции 24; 4) $\mathrm{N}, \mathrm{N}$-диметиланилин (ГОСТ 5855-70); 5) н-бутанол (ГОСТ 6006-73); 6) уксусная кислота (ГОСТ 18270-72); 7) муравьиная кислота (ГОСТ $5848-73)$; 8) хроматографическая бумага марки FN-1 и FN-12 (ГДР). 
Результаты определения хлор-иона

Таблица 1

\begin{tabular}{|c|c|c|c|}
\hline \multirow[b]{2}{*}{ Синтезированные соединения } & \multicolumn{3}{|c|}{ Содержание хлор-иона, \% } \\
\hline & $\begin{array}{l}\text { Суммар- } \\
\text { ное }\end{array}$ & $\begin{array}{l}\text { В виде } \\
\text { соляной } \\
\text { кислоты }\end{array}$ & $\begin{array}{c}\text { В составе } \\
\text { четвер- } \\
\text { тичной } \\
\text { соли } \\
\text { аммония }\end{array}$ \\
\hline $\begin{array}{l}\text { Хлористый геранилдиметилфениламмоний } \\
{\left[\mathrm{C}_{10} \mathrm{H}_{17} \cdot \mathrm{NC}_{8} \mathrm{H}_{11}\right] \mathrm{Cl}\left(\mathrm{C}_{10} \cdot Д \mathrm{MA}\right)}\end{array}$ & 9,1 & 1,8 & 7,3 \\
\hline $\begin{array}{l}\text { Хлористый фарнезилдиметилфениламмоний } \\
{\left[\mathrm{C}_{15} \mathrm{H}_{25} \cdot \mathrm{NC}_{8} \mathrm{H}_{11}\right] \mathrm{Cl}\left(\mathrm{C}_{15} \cdot \text { ДMA) }\right.}\end{array}$ & 3,2 & 1,1 & 2,1 \\
\hline $\begin{array}{l}\text { Смесь четвертичных солей аммония } \\
{\left[\mathrm{H}\left(\mathrm{C}_{5} \mathrm{H}_{8}\right)_{n} \cdot \mathrm{NC}_{8} \mathrm{H}_{11}\right] \mathrm{Cl} \cdot(\mathrm{T} \cdot Д М \mathrm{~A})}\end{array}$ & 8,7 & 1,2 & 7,5 \\
\hline
\end{tabular}

Синтез четвертичных солей аммония проводился по методике $\left[{ }^{1}\right]$. В синтезированных соединениях определялось содержание хлор-иона и содержание хлора, связанного в виде соляной кислоты $\left[{ }^{2}\right]$ (табл. 11).

Для разделения соединений (табл. (1) использовался прибор электрофореза фирмы «Carl Zeiss, Jena». Методика разделения аналогична методике $\left[{ }^{3}\right]$. Спектрофотометрические определения выполнялись на УФ-спектрометре «Specord UV VIS».

\section{Результаты и их обсуждение}

Первые опыты с использованием в качестве буферного раствора уксусной кислоты показали, что смесь хлористых четвертичных солей аммония разделяется в процессе электрофореза на четыре зоны, идентифицируемые при помощи эталонных соединений. Первая зона (отсчет от стартовой линии) относится $\mathrm{K}$ $\mathrm{C}_{15} \cdot$ ДМА, вторая $-\mathrm{k}$ $\mathrm{C}_{10} \cdot$ ДМА, третья и четвертая - к N,N-диметиланилину: при этом третья зона, по-видимому, принадлежит солянокислому NN-диметиланилину, a четвертая - избыточному $\mathrm{N}, \mathrm{N}$-диметиланилину. Присутствие четвертичных солей аммония политерпеновых первичных аллильных хлоридов в исследованной смеси не обнаружено.

Для установления оптимальных условий разделения определялась электрофоретическая подвижность зон $\mathrm{C}_{10} \cdot$ ДМА и $\mathrm{C}_{15} \cdot$ ДМА на бумаге

\section{Электрофоретическая подвижность $\mathrm{C}_{10}$.ДМА и $\mathrm{C}_{15}$.ДМА в зависимости от условий электрофореза}

\begin{tabular}{|c|c|c|c|}
\hline \multirow{2}{*}{$\begin{array}{c}\text { Градиент } \\
\text { потенциала, } \\
B \cdot c M^{-1}\end{array}$} & \multirow{2}{*}{$\begin{array}{c}\text { Время } \\
\text { электрофо- } \\
\text { реза, } 4\end{array}$} & \multicolumn{2}{|c|}{$\begin{array}{c}\text { Электрофоретическая } \\
\text { подвижность, мм }\end{array}$} \\
\hline & & $\mathrm{C}_{10} \cdot$ ДМА & $\mathrm{C}_{15} \cdot$ ДМА \\
\hline
\end{tabular}

$\begin{array}{llll}5,0 & 2,0 & 69 & 42 \\ 6,0 & 2,0 & 79 & 51 \\ 6,7 & 1,5 & 67 & 45 \\ 6,7 & 2,0 & 83 & 55 \\ 6,7 & 2,5 & 97 & 60\end{array}$

$0,2 \mathrm{M} \mathrm{CH}_{3} \mathrm{COOH} ; \quad \mathrm{pH} 2,86$

$\begin{array}{llll}6,7 & 1,5 & 63 & 45 \\ 6,7 & 2,0 & 82 & 55 \\ 6,7 & 2,5 & 90 & 63\end{array}$

$0,5 \mathrm{M} \mathrm{CH}_{3} \mathrm{COOH}, \quad$ pH 2,63

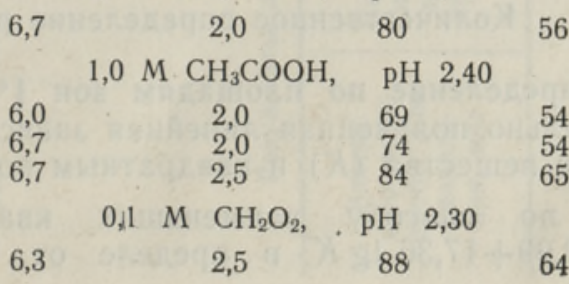



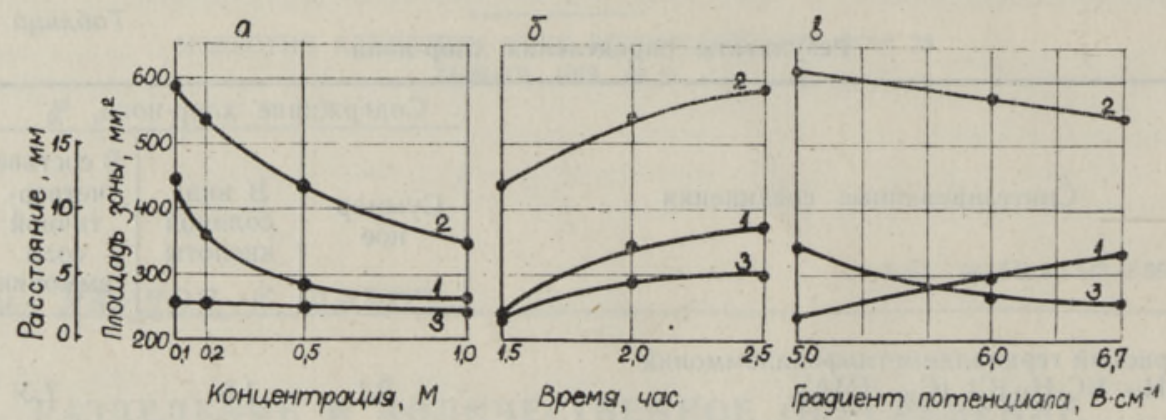

Рис. 1. Расстояние между двумя соседними зонами (1), площадь зоны $\mathrm{C}_{10}$. ДМА (2) и площадь зоны $\mathrm{C}_{15}$.ДМА (3).

FN-1 в варьируемых условиях (табл. 2). Подвижность зоны $\mathrm{C}_{10}$.ДМА уменьшается при увеличении концентрации буферного раствора, а подвижность зоны $\mathrm{C}_{15}$. ДМА не изменяется (табл. 2).

Разрешающая способность, определяемая расстоянием между соседними зонами, и площади зон разделенных компонентов также зависят от условий разделения: концентрации буферного раствора, продолжительности электрофореза и градиента потенциала (рис. $1, a, \sigma$ и в). Представленные на рис. 1 данные получены при использовании в качестве хроматографической бумаги марки FN-1. Для разделения было взято 50 мкट вещества (содержащего 65\% четвертичных солей аммония), нанесенного на ленты бумаги в виде 0,03 М раствора в этиловом спирте при помощи бумажных полосок $2 \times 30$ мм. При варьировании одного из условий разделения другие оставались следующими: концентрация уксусной кислоты $0,2 \mathrm{M}$, продолжительность электрофореза 2 ч и градиент потенциала $6,7 \mathrm{~B} \cdot \mathrm{cm}^{-1}$.

При использовании 0,1 M раствора уксусной кислоты расстояние между зонами почти в 4 раза больше, чем при использовании $1,0 \mathrm{M}$ раствора, в то же время заметно уменьшается и площадь зоны $\mathrm{C}_{10} \cdot$ ДМА (рис. 1).

Принимая во внимание все факторы (подвижность зон, расстояния между зонами, компактность и разграниченность зон, время электрофореза); оптимальными условиями разделения при использовании марки бумаги FN-1 будут: 0,2 M раствор уксусной кислоты при градиенте потенциала $6,7 B \cdot c M^{-1}$ и продолжительности электрофореза 24 .

При использовании 0,5-1,0 M растворов уксусной кислоты разграниченность зон улучшается, но уменьшается расстояние между соседними зонами, и для достижения удовлетворительной резделяемости нужно увеличить время электрофореза до 2,5 ч.

Удовлетворительные результаты получены и при использовании в качестве буферного раствора 0,1 М муравьиной кислоты (табл. 1).

\section{Количественное определение разделенных компонентов}

1. Определение по площадям зон [ $\left.{ }^{4}\right]$. На рис. 2 приведена экспериментально полученная линейная зависимость между логарифмом количества вещества $(K)$ и квадратным корнем из величины площади зоны (S) по способу. наименьших квадратов. Для $\mathrm{C}_{10} \cdot$ ДМА $\sqrt{\mathrm{S}}=$ $=-0,99+17,36 \lg K$ в пределе от 6 до 100 мке. Для $\mathrm{C}_{15} \cdot$ ДМА 


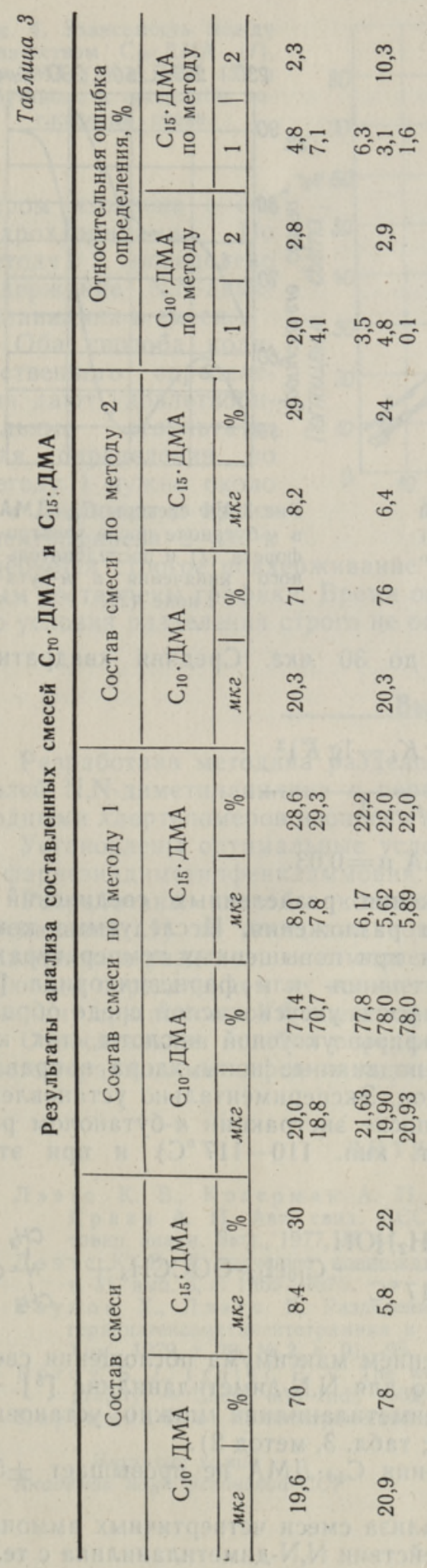

ปั)

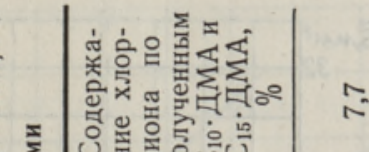

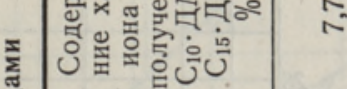

\&๐

ติ

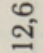

$=$

เே.

$=$

is

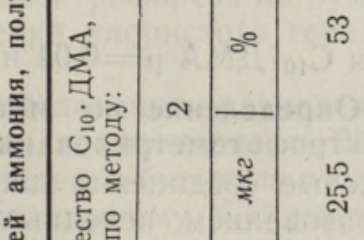

ลุ

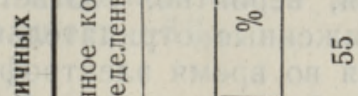

กิ

$\infty$

추ํ

등윰융

$\infty$

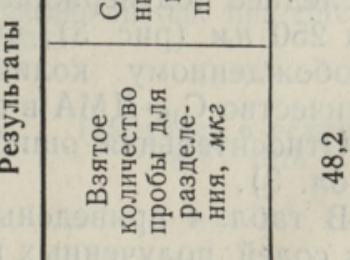




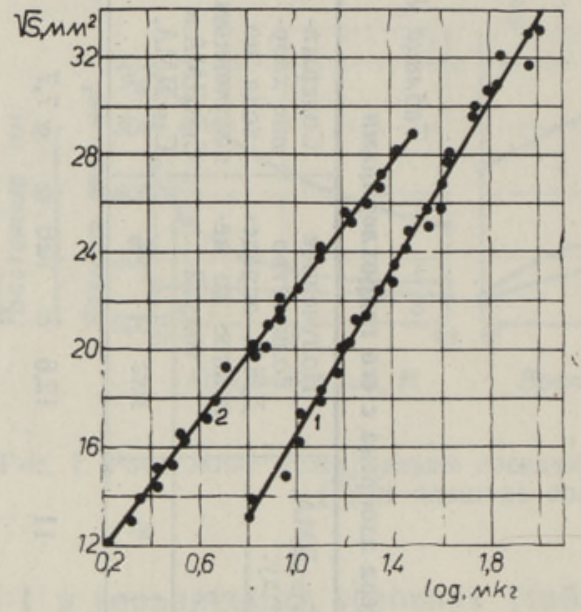

Рис. 2. Зависимость между логарифмом количества $\mathrm{C}_{10}$.ДМА (1) и $\mathrm{C}_{15} \cdot$ ДМА (2) и корнем квадратным из величины площади зон.

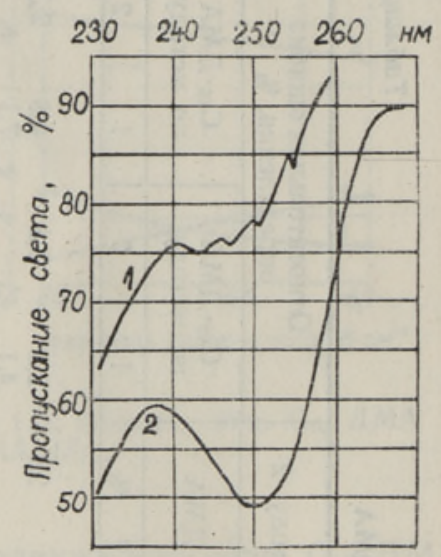

Рис. 3. УФ-спектры $\mathrm{C}_{10}$. ДМА в $н$-бутаноле после электрофореза (1) и последовательного кипячения в $н$-бутаноле (2).

$\sqrt{S}=8,7+13,7 \lg K$ в пределе от 1 до 30 мкг. Средняя квадратная ошибка ( $\mu)$ определения $\lg K$ :

$$
\mu=\sqrt{\frac{\sum_{i=1}^{n}\left(\lg K_{i}-\lg \bar{K}\right)^{2}}{n-1}} .
$$

Для $\mathrm{C}_{10} \cdot$ ДМА $\mu=0,04$ и для $\mathrm{C}_{15} \cdot$ ДМА $\mu=0,03$.

2. Определение по методу разложения разделенных соединений и спектрофотометрирования продуктов разложения. Исследуемые комплексные соединения диссоциируются при повышенных температурах с образованием исходных амина и геранил- или фарнезихлорида [ $\left.{ }^{1}\right]$. В результате электрофореза на бумаге в уксуснокислой среде образуются, вероятно, соответствующие эфиры уксусной кислоты, так как заряженные отрицательно и более подвижные ионы хлора направляются во время электрофореза на анод. Экспериментально установлено, что образовавшиеся эфиры можно после экстракции $н$-бутанолом разложить кипячением в $н$-бутаноле (т. кип. $110-117^{\circ} \mathrm{C}$ ) и при этом возникает свободный амин:<smiles>CC(=O)OCCCCCC(C)C(C)OC(C)=O</smiles>

Последнее подтверждается и появлением максимума поглощения света при 250 нм (рис. 3), что характерно для N,N-диметиланилина [ $\left.{ }^{5}\right]$. По освобожденному количеству $\mathrm{N}, \mathrm{N}$-диметиланилина можно установить количество $\mathrm{C}_{10} \cdot$ ДМА в смеси (рис. 4 ; табл. 3 , метод 2 ).

Относительная ошибка определения $\mathrm{C}_{10}$. ДМА не превышает $\pm 5 \%$ (табл. 3).

В табл. 4 приведены данные анализа смеси четвертичных аммониевых солей, полученных при взаимодействии N,N-диметиланилина с тело- 
Рис. 4. Зависимость между количеством $\mathrm{C}_{10} \cdot$ ДМА (1), $\mathrm{C}_{15}$. ДМА (2) и ДМА (3) в н-бутаноле и процентом поглощения света.

мером изопрена с его гидрохлоридами. По методу 2 определено содержание N,N-диметиланилина в смеси.

Оба способа количественного определения дают удовлетворительные результаты. Для определения по методу 1 нужно около 3 ч (включая и время

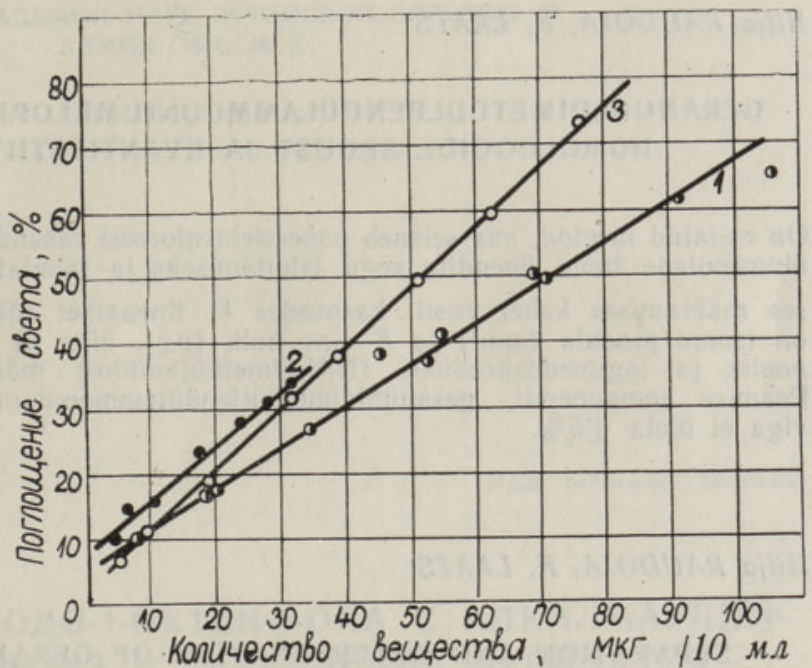
электрофореза 2 и) и требуется строгое поддерживание тех условий электрофореза, по которым составлены графики. Время определения по методу 2 - около 5 , но условия разделения строго не ограничиваются.

\section{Выводы}

1. Разработана методика разделения смеси четвертичных аммониевых солей N,N-диметиланилина с первичными аллильными галогенопроизводными хлортеломеров изопрена при помощи электрофореза на бумаге. 2. Установлены оптимальные условия разделения хлористого геранили фарнезилдиметилфениламмония.

3. Разработаны способы количественного определения разделенных соединений: 1) по площадям зон разделенных компонентов и 2) по разложению разделенных компонентов кипячением в $н$-бутаноле с последующим определением их количества по освобожденному $\mathrm{N}, \mathrm{N}$-диметиланилину при помощи УФ-спектрофотометра.

4. Относительная ошибка определения главного компонента - хлористого геранилдиметилфениламмония - не превышает $\pm 5 \%$.

\section{Л И Т Е Р А Т У Р А}

1. Лээтс К. В., Когерман А. П., Кудрявцев И. Б., Таммару У. Я., К р а а в А. П. Авт. свид. СССР № 582241. - Изобретения, открытия и товар. знаки. Бюл., 1977, № 44.

2. Л э э т с К. В. К изучению ионно-каталитической теломеризации. - ЖОХ, 1961, т. 31 , вып. 6 , с. $1869-1876$.

3. Р аудоя Х., Лээтс К. Разделение и количественное определение хлористого геранилгексаметилентетрамина в смеси с его гомологами. - Изв. АН ЭССР. Хим., 1979, т. 28 , № 2 , с. $91-95$.

4. Purdy, S. J., Truter, E. V. The weight area relationship in thin film chromatography. - Chem. and Ind., 1962, N 11, p. 506-507.

5. Корен м а н И. М. Фотометрический анализ. М., 1975.

Ннститут химии

Академии наук Эстонской ССР
Поступила в редакцию 8/VI 1978 
Hilja RAUDOJA, K. LAATS

\section{GERANUULDIMETUULFENUOLAMMOONIUMKLORIIDI LAHUTAMINE TEMA HOMOLOOGIDE SEGUST JA KVANTITATIIVNE MÄÄRAMINE}

On esitatud meetod, mis seisneb paberelektroforeesi rakendamises kvaternaarsete ammooniumsoolade tüüpi ühendite segu lahutamiseks ja lahutatud komponentide kvantitatiivses määramises kahel viisil: kasutades 1) lineaarset sōltuvust $\sqrt{S}=a-b \cdot \lg K$, kus $S$ on tsooni pindala $\left(\mathrm{mm}^{2}\right)$ ja $K$ aine hulk $(\mu \mathrm{g})$, ning 2) lagundamist keetmisel $n$-butanoolis ja lagunemisprodukti ( $\mathrm{N}, \mathrm{N}$-dimetüülaniliini) määramist spektrofotomeetriliselt. Peamise komponendi, geranüüldimetüülfenüülammooniumkloriidi määramise suhteline viga ei ületa $\pm 5 \%$.

Hilja RAUDOJA, K. LAATS

\section{SEPARATION AND DETERMINATION OF GERANYLDIMETHYLPHENYL- AMMONIUM CHLORIDE IN THE MIXTURE OF ITS HOMOLOGUES}

A new separation and determination method of geranyldimethylphenylammonium chloride in the mixture of its homologues is presented. The separation was carried out by paper electrophoresis. Determination of the separated products was carried out in two ways: (1) by the area of the zone of the separated component, (2) the separated component was decomposed by boiling in $n$-butyl alcohol and the released equivalent quantity of $\mathrm{N}, \mathrm{N}$-dimethylaniline was determined spectrophotometrically. 